\title{
Effects of season, age and body condition on allocation to testes mass in Iberian ibex
}

\author{
M. Sarasa ${ }^{1,2}$, E. Serrano ${ }^{3}$, J. M. Pérez ${ }^{1}$, R. C. Soriguer ${ }^{4}$, G. Gonzalez ${ }^{2}$, J. Joachim ${ }^{2}$, P. Fandos ${ }^{5}$ \& \\ J.-E. Granados ${ }^{6}$ \\ 1 Departamento de Biología Animal, Biología Vegetal y Ecología, Facultad de Ciencias Experimentales, Universidad de Jaén, Jaén, Spain \\ 2 Laboratoire Comportement et Ecologie de la Faune Sauvage, Institut National de la Recherche Agronomique, Castanet-Tolosan, France \\ 3 Servei d'Ecopatologia de Fauna Salvatge, Facultat de Veterinària, Universitat Autònoma de Barcelona, Bellaterra, Spain \\ 4 Estación Biológica de Doñana, Sevilla, Spain \\ 5 EGMASA, Isla de la Cartuja, Sevilla, Spain \\ 6 Espacio Natural Sierra Nevada, Pinos Genil, Granada, Spain
}

\section{Keywords}

Capra pyrenaica; mating tactic; phenotypic plasticity; sperm competition; testis; ungulate.

\section{Correspondence}

Mathieu Sarasa, Departamento de Biología Animal, Biología Vegetal y Ecología, Facultad de Ciencias Experimentales, Universidad de Jaén, E-23071 Jaén, Spain. Email:mathieusar@hotmail.com

Editor: Virginia Hayssen

\begin{abstract}
Sperm competition is a powerful evolutionary force, and understanding the factors that regulate testes characteristics may lead to a better understanding of the variability in male reproductive success. We explored the effects of age, body condition and season on relative testes mass in the Iberian ibex Capra pyrenaica. We analysed the variability of testes mass from 175 individuals, using a model selection approach based on Akaike's information criterion corrected for a small sample size. The results suggest that season, age and body condition influenced relative testes mass. Allocation to testes mass was greatest in the rutting season (autumn) and at ages that are associated with a subordinate status and a coursing, rather than mate-guarding, reproductive strategy. In addition, males in good condition had relatively heavier testes than those in poor condition. Thus, testes mass in Iberian ibex is governed by multiple factors, and this study leads to a better understanding of gonad plasticity in this polygamous ungulate. The effect of age matches the predictions from theoretical studies on sperm competition, which suggests greater allocation to testes in disadvantaged males.
\end{abstract}

\section{Introduction}

Testes size is linked to mating strategies (Harcourt et al., 1981; Harcourt, Purvis \& Liles, 1995) and reproductive success (Schulte-Hostedde \& Millar, 2004) via sperm competition (Birkhead \& Møller, 1998). More specifically, multimale mating systems are associated with relatively larger testes than single-male mating systems (Reynolds \& Harvey, 1994; Harcourt et al., 1995). Larger testes provide an advantage in terms of sperm competition (Scharer, Ladurner \& Rieger, 2004; Scharer \& Vizoso, 2007) and maximize reproductive success (Preston et al., 2003; Schulte-Hostedde \& Millar, 2004).

Intra-specific variations in mating tactics may also affect testes (Awata et al., 2006). In seasonal breeding species, testes size (and correlated traits) often vary throughout life (Gupta et al., 2000). In addition, body condition is generally positively correlated with testes size (Schulte-Hostedde, Millar \& Hickling, 2003; Schulte-Hostedde \& Millar, 2004).

Testes size is positively correlated with male reproductive success (Preston et al., 2003). Ungulates display large variations in sex-specific reproductive success (Vanpe et al.,
2008), but few studies have examined the causes and consequences of testes size in wild species (but see Ginsberg \& Rubenstein, 1990; Preston et al., 2003).

Like other caprines (Couturier, 1962; Grubb, 1974; Nievergelt, 1974; Schaller, 1977; Habibi, 1994; Preston et al., 2003; Pelletier, Hogg \& Festa-Bianchet, 2006), the Iberian ibex Capra pyrenaica is a medium-sized polygamous ungulate in which rutting is characterized by direct conflicts over access to females and mate-guarding is a primary tactic (Alados, 1986; Alvarez, 1990). As in closely related species (Couturier, 1962; Grubb, 1974; Nievergelt, 1974; Schaller, 1977; Habibi, 1994; Preston et al., 2003; Pelletier et al., 2006), the most successful tactic, 'tending', involves guarding of a single oestrous female (Couturier, 1962; Pelletier et al., 2006). Subordinate males will attempt to take advantage of any separation between an oestrous female and the dominant male. Separation may occur when the dominant male is in combat with other males, which may lead to rapid malefemale chases during which males attempt to force copulation with the oestrous female. This strategy of male-female chases with attempts of forced copulation is called the 'coursing' mating tactic (Couturier, 1962; Pelletier et al., 2006). 
In this study, we examined the correlative factors of testes mass in Iberian ibex and tested predictions from different hypotheses.

(1) According to the 'terminal investment' hypothesis (Clutton-Brock, 1984), as males age, their residual reproductive value decreases. Hence, males should increase their investment in reproduction (Williams, 1966; Pianka \& Parker, 1975) and their allocation to testes mass.

(2) Based on the 'male mating strategy' (Pelletier et al., 2006), the allocation to testes mass should peak in males using the mating tactic with the highest reproductive success (tending in caprines; Couturier, 1962; Nievergelt, 1974; Habibi, 1994; Hogg \& Forbes, 1997; Pelletier et al., 2006).

Despite being based on different theoretical concepts, both hypotheses 1 and 2 predict a greater allocation to testes in older males.

(3) Disadvantaged males (due to dominance or female choice) should invest more in ejaculate and testes size compared with favoured males (Parker, 1990; Tazzyman et al., 2009). In caprines, tending males guard females and perform 'retaliatory' copulations after regaining control of an oestrous female that was chased by coursing males (Couturier, 1962; Hogg, 1988). Consequently, coursing males may be under selective pressure, and, according to theoretical studies of sperm competition (Parker, 1990; Tazzyman et al., 2009), allocation to testes mass should peak in subordinate young males.

(4) As nutrition and body condition are usually positively correlated with testes size (Schulte-Hostedde \& Millar, 2004; Schulte-Hostedde, Millar \& Hickling, 2005a; Brito et al., 2007), animals in good condition should have larger testes than those in poor condition.

(5) Like other organs (Piersma \& Lindstrom, 1997; Piersma \& Drent, 2003), testes show seasonal phenotypic plasticity (Nigi et al., 1980; Glover, D’Occhio \& Millar, 1990). Testes are larger during the rut in ungulates (Couturier, 1962) and the Iberian ibex may have a seasonal pattern characterized by greater allocation to testes mass in the autumn.

\section{Materials and methods}

\section{Study site and population}

We analysed testes mass in male Iberian ibex from the Sierra Nevada mountain range $\left(36100^{\circ}-37110^{\circ} \mathrm{N}, 2134^{\circ}-3140^{\circ} \mathrm{W}\right.$, southern Spain) in 1995-1998, 2000-2003, 2007 and 2008. This population was intensively monitored (Perez, Granados \& Soriguer, 1994; Perez et al., 1997), and animals were culled by National Park (Espacio Natural de Sierra Nevada) staff for research and management purposes. We used data from 175 macroscopically healthy males. After culling, each individual was weighed to the nearest $500 \mathrm{~g}$ and shoulder height was measured to the nearest $0.5 \mathrm{~cm}$. Age was assessed based on horn segment counts (Fandos, 1991). During necropsy, the testes were removed and weighed to the nearest $0.01 \mathrm{~g}$. The arithmetic mean of the two testicles was used as the overall testicular mass.

\section{Analysis}

Given that age is closely correlated with mating strategy in caprines (Couturier, 1962; Grubb, 1974; Habibi, 1994; Pelletier et al., 2006), we used age as an indicator of mating tactics. Coursing is used by subordinate young males and guarding is used by older dominant males (Couturier, 1962; Grubb, 1974; Habibi, 1994; Pelletier et al., 2006).

To examine the relative effects of age, body condition and season, we estimated several residuals (detailed below), and in each case, chose the best-fitting regression between linear and non-linear models based on Akaike's information criterion (AIC - a tool for model selection; Burnham \& Anderson, 2002). We log-transformed $\left(\log _{10}\right)$ body mass and testes mass to normalize the data (Shapiro-Wilk test). Shoulder height is an important growth parameter during the skeletal development of Iberian ibex (Fandos, 1991). We controlled for allometry in testes mass using residuals from linear regression of the log-transformed arithmetic mean of the mass of the two testes on shoulder height (Schulte-Hostedde et al., 2005b) as the dependent variable in all our analyses. We defined seasons as follows: winter (15 December to 5 March), spring (6 March to 15 June), summer (16 June to 15 September) and autumn (16 September to 14 December) (Consejerı de Medio Ambiente, 2004). To account for seasonality in body condition, we calculated the residuals of the linear regression of logtransformed body mass on shoulder height (Schulte-Hostedde et al., 2005b) fitted separately for each season. We controlled for expected effects of age on body condition (Harper, 1998; Kojola, et al., 1998; Kyle et al., 2001) and observed a nonlinear relationship between the two factors [residual sum of squares of the fitted model (RSS) $=3.799$ ]. Consequently, we used the residuals of the fitted logistic regression of seasonalspecific body condition on age as the body condition index.

To test the effects of age, body condition and season on the allocation to testes mass, we used generalized additive mixed models (Wood, 2006; Zuur, Ieno \& Smith, 2007), using an information-theoretic approach based on AIC corrected for a small sample size (AIC $\mathrm{C}_{\mathrm{c}}$; Burnham \& Anderson, 2002). The sampling period was introduced into models as the month at which each individual was culled (coded as 12 months). Year was also included as a random factor (Wood, 2006). The analysis identified the mostparsimonious model (lowest $\mathrm{AIC}_{\mathrm{c}}$ ) of all possible subsets, ranging from the null model (MO, intercept only) to a model with explanatory variables and two-order interactions. The relative importance (RI) of the explanatory variables was examined to highlight evidence for the importance of each variable within the set of models (Anderson, Burnham \& Thompson, 2000; Anderson et al., 2001; Burnham \& Anderson, 2002). Adjusted $\mathrm{R}^{2}$ values, providing an estimate of the model fit (Wood, 2006), are also presented.

\section{Results}

Season (S), age (A) and body condition (BC) were found to influence allocation to testes mass in Iberian ibex. According to our model selection procedure, the best model was 
Table 1 Model selection for determining factors of relative testes mass in Iberian ibex Capra pyrenaica

\begin{tabular}{|c|c|c|c|c|c|c|c|c|c|}
\hline Model & Sample size & $\mathrm{K}$ & $\mathrm{AlC}_{\mathrm{c}}$ & Di & $\mathrm{L}(\mathrm{gi} / \mathrm{x})$ & $\mathrm{Wi}$ & $R^{2}$ (adj) & $\mathrm{RI}$ & \\
\hline$\overline{S+A+B C+S^{x} A}$ & 175 & 9 & -89.75 & 0 & 1 & 0.41 & 0.82 & $\mathrm{~S}$ & 1 \\
\hline $\mathrm{S}+\mathrm{A}+\mathrm{BC}+\mathrm{S}^{\times} \mathrm{BC}$ & 175 & 9 & -87.86 & 1.89 & 0.39 & 0.16 & 0.82 & $\mathrm{BC}$ & 1 \\
\hline$S+A+B C+S^{x} A+A^{x} B C$ & 175 & 10 & -87.52 & 2.24 & 0.33 & 0.14 & 0.82 & A & 1 \\
\hline$S+A+B C+S^{\times} A+S^{\times} B C$ & 175 & 10 & -87.50 & 2.25 & 0.32 & 0.13 & 0.82 & $S^{\times} A$ & 0.84 \\
\hline$S+A+B C+S^{x} B C+A^{x} B C$ & 175 & 10 & -86.75 & 3.00 & 0.22 & 0.09 & 0.82 & $S^{\times} B C$ & 0.60 \\
\hline$S+A+B C+S^{\times} A+S^{\times} B C+A^{\times} B C$ & 175 & 11 & -85.24 & 4.52 & 0.10 & 0.04 & 0.82 & $A^{\times} B C$ & 0.28 \\
\hline$S+A+B C$ & 175 & 7 & -82.89 & 6.86 & 0.03 & 0.01 & 0.83 & & \\
\hline$S+A+B C+A^{x} B C$ & 175 & 8 & -81.44 & 8.31 & 0.02 & 0.01 & 0.83 & & \\
\hline$S+B C+S^{\times} B C$ & 175 & 8 & -67.89 & 21.87 & 0 & 0 & 0.76 & & \\
\hline$S+A+S^{x} A$ & 175 & 7 & -63.63 & 26.12 & 0 & 0 & 0.79 & & \\
\hline
\end{tabular}

Relative testes mass is corrected for allometry.

$\mathrm{S}$, season; A, age; BC, body condition; ${ }^{\times}$, interaction; MO, null model; K, number of estimated parameters; $\mathrm{AlC}_{\mathrm{c}}$, Akaike's Information Criterion corrected for small sample size; DAIC ${ }_{c}$, difference of $\mathrm{AIC}_{\mathrm{c}}$ between the model and the most-parsimonious model; $\mathrm{L}(\mathrm{gi} / \mathrm{x})$, probability of the model being the Kullback-Leibler best model given the dataset; Wi, Akaike weight of the model; $R^{2}$ (adj), adjusted $R^{2}$ of the fitted model; $R I$, relative importance of factors. Only the 10 best models are reported; see Burnham \& Anderson (2002) and Wood (2006).

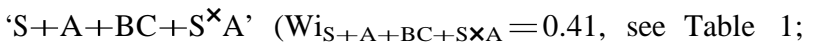
$\mathrm{Wi}=$ Akaike weight of the model), followed by ' $\mathrm{S}+\mathrm{A}+\mathrm{BC}+\mathrm{S}^{\times} \mathrm{BC}$ ' $\left(\mathrm{Wi}_{\mathrm{S}+\mathrm{A}+\mathrm{BC}+\mathrm{S} \times \mathrm{BC}}=0.16\right.$, see Table 1$)$. Allocation to testes mass was season dependent, peaking in the month before rutting (October) and reaching its lowest point in spring (Fig. 1). Size-corrected testes mass also varied with age, but with season-dependent trends as suggested by the interaction between season and age in the best model (Fig. 2). From winter to summer, relative testes mass was positively correlated with age, whereas in autumn (the rutting season) allocation to testes peaked in males that were near their asymptotic skeletal development (4-6 years old; Couturier, 1962; Fandos, 1991; Serrano, Gallego \& Perez, 2004). Body condition was positively correlated with relative testes mass, although the slope of this relationship may be season dependent, as suggested by the second model $\left(\right.$ DAIC $_{\mathrm{C}} \mathrm{S}+\mathrm{A}+\mathrm{BC}+\mathrm{S} \times \mathrm{BC}=1.89$; Fig. 3).

All the best-ranked models included all explanatory variables. Thus, season, body condition and age had an RI equal to 1 . By contrast, the RIs of the interactions between season and age $\left(\mathrm{S}^{\times} \mathrm{A}\right)$ and between season and body condition $\left(S^{\times} B C\right)$ were higher than the $\mathrm{RI}$ of the interaction between age and body condition $\left(\mathrm{A}^{\times} \mathrm{BC}\right)$ (Table 1$)$. Finally, estimates of the adjusted $R^{2}$ of the fitted models were high (Table 1), and thus the factors explained a great proportion of the variability in testes mass (about 80\%). Data on mean testes and body mass provide a comparison with other species (Appendix S1).

\section{Discussion}

The present results provide evidence that testes mass varies with the season, age and body condition in Iberian ibex. Previous studies of sperm competition and evolution of testes size in ungulates examined behavioural traits that optimize sperm deposition in relation to mating tactics (Hogg, 1988; Ginsberg \& Rubenstein, 1990) or the relationship between testes size and reproductive success (Preston et al., 2003).

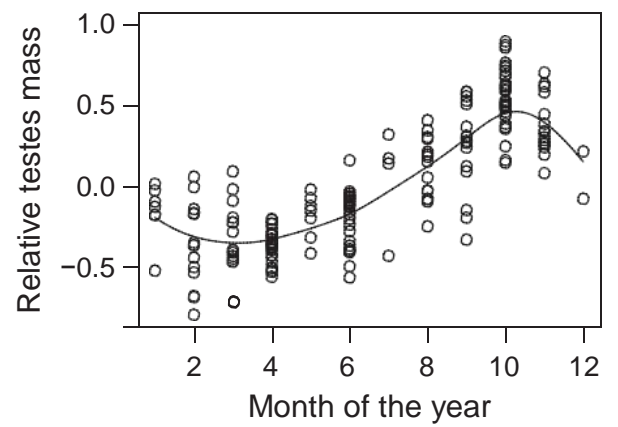

Figure 1 Effect of season on relative testes mass (corrected for body size) in Iberian ibex Capra pyrenaica (Sierra Nevada, Spain), according to the selected generalized additive mixed model (the solid line represents the estimated pattern and the dotted lines indicate 95\% confidence intervals; Wood, 2006).

\section{Testes mass, age and mating tactics}

In several caprids, including the Iberian ibex, mate-guarding (tending) is the primary mating tactic (Couturier, 1962; Pelletier et al., 2006). The use of this tactic increases with rank (Pelletier et al., 2006), which is also positively correlated with age (Couturier, 1962; Grubb, 1974; Habibi, 1994; Pelletier \& Festa-Bianchet, 2006). Relative testes mass in autumn peaked in males that were near their asymptotic skeletal development. This result contradicts predictions based on 'terminal investment' (Clutton-Brock, 1984) and the 'male mating strategy' (Pelletier et al., 2006), but matches predictions from theoretical studies on sperm competition games (Parker, 1990; Tazzyman et al., 2009). In Iberian ibex, allocation to testes mass was higher at ages linked to subordinate status. In subordinate males, the coursing mating tactic prevails in caprines (Couturier, 1962; Grubb, 1974; Habibi, 1994; Pelletier \& Festa-Bianchet, 2006). Theoretical studies on sperm competition predict that disadvantaged males should invest more in ejaculate and testes size compared with favoured males 

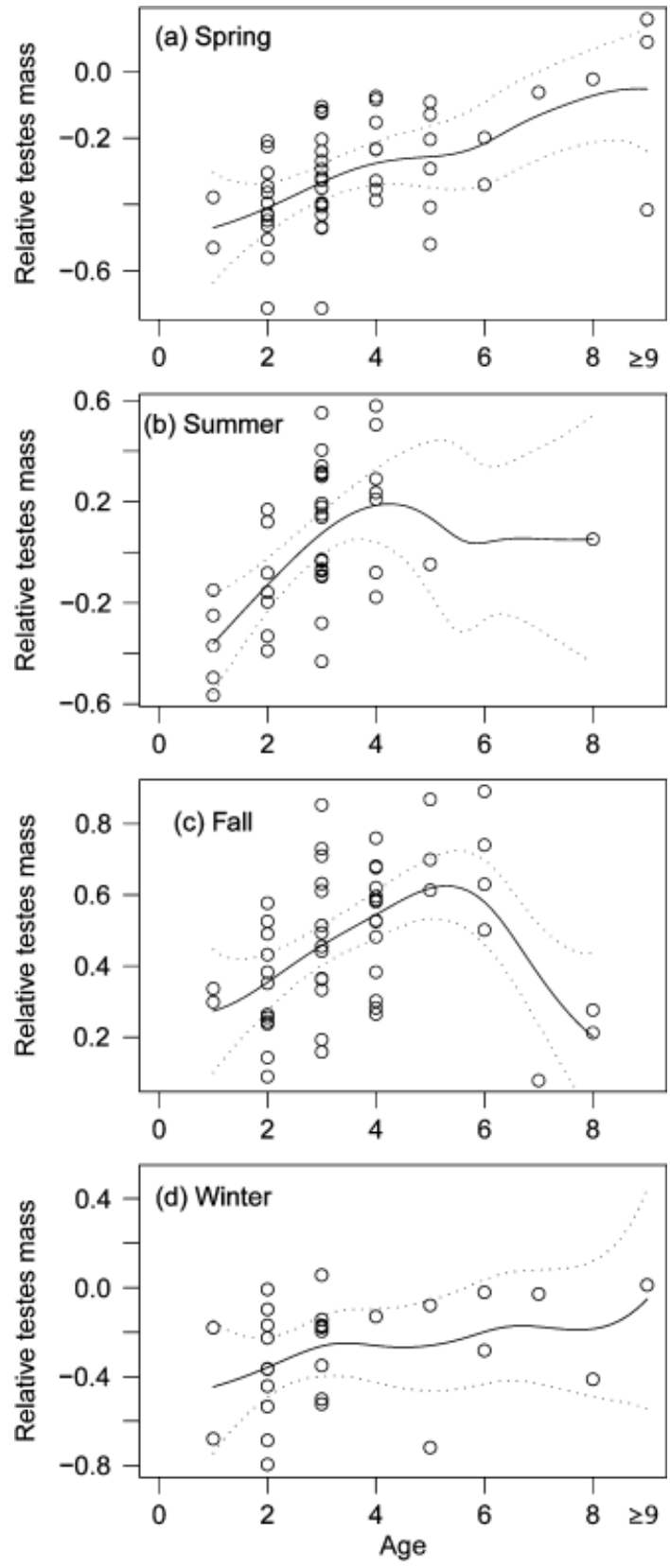

Figure 2 Effect of age on relative testes mass (corrected for body size) in Iberian ibex Capra pyrenaica (Sierra Nevada, Spain), in (a) spring, (b) summer, (c) autumn and (d) winter (the solid line represents the estimated pattern and the dotted lines indicate 95\% confidence intervals; Wood, 2006).

(Parker, 1990; Tazzyman et al., 2009). This is supported by our study of Iberian ibex. Coursing males may compensate for lower access to females (Couturier, 1962; Hogg \& Forbes, 1997) by increasing testis investment. This agedependent testis investment may explain the significant number of paternities assigned to young and subordinate males (Coltman et al., 1999, 2002; Wroblewski et al., 2009).
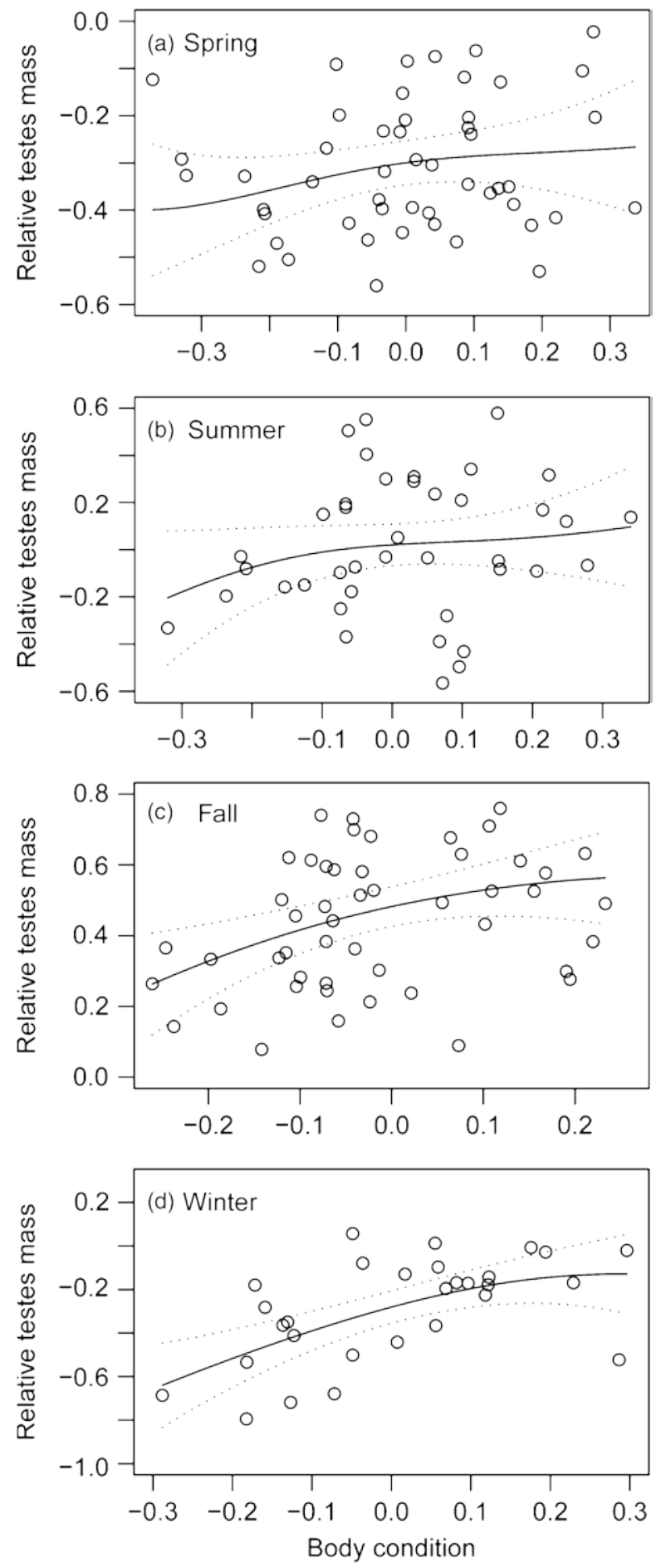

Figure 3 Effect of body condition on relative testes mass (corrected for body size) in Iberian ibex Capra pyrenaica (Sierra Nevada, Spain), in (a) spring, (b) summer, (c) autumn and (d) winter (the solid line represents the estimated pattern and the dotted lines indicate 95\% confidence intervals; Wood, 2006). 
Larger testes are probably advantageous when dominant males cannot control access to all oestrous females (Preston et al., 2003).

Once males reached their asymptotic mass, social rank, which also depends on the phenotypic quality and on the fine-scale age structure of the population, is more closely correlated with mating tactics than age (Pelletier et al., 2006). Hence, further analysis of the determining factors of testes mass should include this behavioural dimension. A role for senescence might explain the decrease in relative testes mass in older animals. However, only one male in our sample was over 10 years old, and senescence only becomes evident in ibexes at about 10-12 years of age (Couturier, 1962; Schaller, 1977; To1go et al., 2007).

\section{Testes mass, seasonality and phenotypic plasticity}

Caprids are seasonal breeders (Couturier, 1962; Nievergelt, 1974; Schaller, 1977) and, as expected on the basis of testicular activity and plasma testosterone concentrations (Toledano-Diaz et al., 2007), allocation to testes mass was the highest in the autumn in Iberian ibex and declined considerably thereafter. Testes investment and increased testosterone levels may favour muscular mass (SchulteHostedde et al., 2003) and aggressiveness (Muller \& Wrangham, 2004; Archer, 2006). Increased muscular mass, aggressiveness, testes size and testosterone levels probably improve male reproductive success in social species with limited mate access (Couturier, 1962; Grubb, 1974; Habibi, 1994; Pelletier et al., 2006) and high intra-group competition (Krause \& Ruxton, 2002). Investing earlier in testes and then maintaining larger testes might confer preferential access to precocious oestrous females or to food during periods of seasonal scarcity. The interaction between body condition and season in Iberian ibex suggests that males in good condition might invest earlier and then maintain testis investment. This inter-individual variability in testes investment is likely to affect the temporal variation in reproductive effort and in siring success (Preston et al., 2001; Mysterud et al., 2008) and might be relevant for interindividual heterogeneity in testosterone-linked immunodepression and reproductive costs (Zuk, 1996; Klein, 2000; Sinervo \& Clobert, 2008; Grear, Perkins \& Hudson, 2009).

The present results suggest that testis investment in Iberian ibex is controlled by several factors, and we provide empirical evidence supporting predictions from theoretical studies on sperm competition games (Parker, 1990; Tazzyman et al., 2009).

\section{Acknowledgements}

We thank the Consejeria de Medio Ambiente de la Junta de Andalucia and in particular the Espacio Natural de Sierra Nevada (ENSN) for logistic support. Special thanks are due to the park wardens and fieldworkers at the ENSN, particularly to Apolo Sanchez Lao, Jose Lopez Perez, Isidro Puga
Gonzalez, Elias Martınez Ortız, Francisco Javier Perez Diaz, Francisco Casado Felipe, Antonio Jose Rodriguez Duenas and Antonio Rodriguez Huete, for their professional and personal involvement in the study area. We also thank Michael Lockwood, Agnes Sarasa and Paul C. Cross (University Way, USA) for revision of the English text. A.J. Mark Hewison (INRA-CEFS, France) provided valuable suggestions, and Sylvain Losdat (University of Berne, Switzerland) and Cedric Girard-Buttoz (German Primate Centre, Germany) made valuable comments on an earlier draft of this paper. We are also grateful to Marco Festa-Bianchet, Virginia Hayssen and an anonymous reviewer for constructive suggestions on a previous draft. M.S. was supported by a MENRT grant (France) and E.S. by the Juan de la Cierva programme (MICINN, Spain). The research activities of J.E.G., R.C.S. and J.M.P. are also partially supported by the Plan Andaluz de Investigacion (RNM-118). This study was performed in compliance with Spanish laws.

\section{References}

Alados, C.L. (1986). Aggressive behaviour, sexual strategies and their relation to age in male Spanish ibex (Capra pyrenaica). Behav. Process. 12, 145-158.

Alvarez, F. (1990). Horns and fighting in male Spanish ibex, Capra pyrenaica. J. Mamm. 71, 608-616.

Anderson, D.R., Burnham, K.P. \& Thompson, W.L. (2000). Null hypothesis testing: problems, prevalence, and an alternative. J. Wildl. Mgmt. 64, 912-923.

Anderson, D.R., Link, W.A., Johnson, D.H. \& Burnham, K.P. (2001). Suggestions for presenting the results of data analyses. J. Wildl. Mgmt. 65, 373-378.

Archer, J. (2006). Testosterone and human aggression: an evaluation of the challenge hypothesis. Neurosci. Biobehav. Rev. 30, 319-345.

Awata, S., Heg, D., Munehara, H. \& Kohda, M. (2006). Testis size depends on social status and the presence of male helpers in the cooperatively breeding cichlid Julidochromis ornatus. Behav. Ecol. 17, 372-379.

Birkhead, T.R. \& Møller, A.P. (1998). Sperm competition and sexual selection. San Diego: Academic Press.

Brito, L.F.C., Barth, A.D., Rawlings, N.C., Wilde, R.E., Crews, D.H., Boisclair, Y.R., Ehrhardt, R.A. \& Kastelic, J.P. (2007). Effect of feed restriction during calfhood on serum concentrations of metabolic hormones, gonadotropins, testosterone, and on sexual development in bulls. Reproduction 134, 171-181.

Burnham, K.P. \& Anderson, D.R. (2002). Model selection and multimodel inference. A practical information-theoretic approach. New York: Springer.

Clutton-Brock, T.H. (1984). Reproductive effort and terminal investment in iteroparous animals. Am. Nat. 123, 212-229.

Coltman, D.M., Bancroft, D.R., Robertson, A., Smith, J.A., Clutton-Brock, T.H. \& Pemberton, J.M. (1999). Male reproductive success in a promiscuous mammal: 
behavioural estimates compared with genetic paternity. Mol. Ecol. 8, 1199-1209.

Coltman, D.W., Festa-Bianchet, M., Jorgenson, J.T. \& Strobeck, C. (2002). Age-dependent sexual selection in bighorn rams. Proc. Roy. Soc. Lond. Ser. B 269, 165-172.

Consejerıa de Medio Ambiente. (2004). Sierra Nevada: basic data. Granada: Grupo Entorno.

Couturier, M. (1962). Le bouquetin de Alpes (Capra aegagrus ibex ibex L.). Grenoble: Arthaud.

Fandos, P. (1991). La cabra montés (Capra pyrenaica) en el Parque Natural de las Sierras de Cazorla, Segura y las Villas. Madrid: ICONA-CSIC.

Ginsberg, J.R. \& Rubenstein, D.I. (1990). Sperm competition and variation in zebra mating behavior. Behav. Ecol. Sociobiol. 26, 427-434.

Glover, T.D., D’Occhio, M.J. \& Millar, R.P. (1990). Male life cycle and seasonality. In Marshall's physiology of reproduction. Vol. 2. Reproduction in the male, 4th edn: 213-378. Lamming, G.E. (Ed.). Edinburgh: Churchill Livingstone.

Grear, D.A., Perkins, S.E. \& Hudson, P.J. (2009). Does elevated testosterone result in increased exposure and transmission of parasites? Ecol. Lett. 12, 528-537.

Grubb, P. (1974). The rut and behaviour of soay rams. In Island survivors: the ecology of the Soay sheep of St Kilda: 200-235. Jewell, P.A., Milner, C. \& Boyd, J.M. (Eds). London: Athlone Press.

Gupta, G., Maikhuri, J.P., Setty, B.S. \& Dhar, J.D. (2000). Seasonal variations in daily sperm production rate of rhesus and bonnet monkeys. J. Med. Primatol. 29, 411-414.

Habibi, K. (1994). The desert ibex. London: IMMEL Publishing.

Harcourt, A.H., Harvey, P.H., Larson, S.G. \& Short, R.V. (1981). Testis weight, body weight and breeding system in primates. Nature 293, 55-57.

Harcourt, A.H., Purvis, A. \& Liles, L. (1995). Sperm competition: mating system, not breeding season, affects testes size of primates. Funct. Ecol. 9, 468-476.

Harper, E.J. (1998). Changing perspectives on aging and energy requirements: aging, body weight and body composition in humans, dogs and cats. J. Nutr. 128, 2627S-2631S.

Hogg, J.T. (1988). Copulatory tactics in relation to sperm competition in Rocky mountain bighorn sheep. Behav. Ecol. Sociobiol. 22, 49-59.

Hogg, J.T. \& Forbes, S.H. (1997). Mating in bighorn sheep: frequent male reproduction via a high-risk 'unconventional' tactic. Behav. Ecol. Sociobiol. 41, 33-48.

Klein, S.L. (2000). The effects of hormones on sex differences in infection: from genes to behavior. Neurosci. Biobehav. Rev. 24, 627-638.

Kojola, I., Helle, T., Huhta, E. \& Niva, A. (1998). Foraging conditions, tooth wear and herbivore body reserves: a study of female reindeer. Oecologia 117, 26-30.

Krause, J. \& Ruxton, G.D. (2002). Living in groups. New York: Oxford University Press.
Kyle, U.G., Genton, L., Hans, D., Karsegard, V.L., Michel, J.P., Slosman, D.O. \& Pichard, C. (2001). Total body mass, fat mass, fat-free mass, and skeletal muscle in older people: cross-sectional differences in 60-year-old persons. J. Am. Geriat. Soc. 49, 1633-1640.

Muller, M.N. \& Wrangham, R.W. (2004). Dominance, aggression and testosterone in wild chimpanzees: a test of the 'challenge hypothesis'. Anim. Behav. 67, 113-123.

Mysterud, A., Bonenfant, C., Loe, L.E., Langvatn, R., Yoccoz, N.G. \& Stenseth, N.C. (2008). The timing of male reproductive effort relative to female ovulation in a capital breeder. J. Anim. Ecol. 77, 469-477.

Nievergelt, B. (1974). A comparison of rutting behaviour and grouping in the Ethiopian and alpine ibex. In The behaviour of ungulates and its relation to management: 324-340. Geist, V. \& Walther, F. (Eds). Morges: International Union for Conservation of Nature.

Nigi, H., Tiba, T., Yamamoto, S., Floescheim, Y. \& Ohsawa, N. (1980). Sexual maturation and seasonal changes in reproductive phenomena of male Japanese monkeys (Macaca fuscata) at Takasakiyama. Primates 21, 230-240.

Parker, G.A. (1990). Sperm competition games: raffles and roles. Proc. Roy. Soc. Lond. Ser. B 242, 120-126.

Pelletier, F. \& Festa-Bianchet, M. (2006). Sexual selection and social rank in bighorn rams. Anim. Behav. 71, 649-655.

Pelletier, F., Hogg, J.T. \& Festa-Bianchet, M. (2006). Male mating effort in a polygynous ungulate. Behav. Ecol. Sociobiol. 60, 645-654.

Perez, J.M., Granados, J.E. \& Soriguer, R.C. (1994). Population dynamic of the Spanish ibex Capra pyrenaica in sierra Nevada natural park (southern Spain). Acta Theriol. 39, 289-294.

Perez, J.M., Ruiz, I., Granados, J.E., Soriguer, R.C. \& Fandos, P. (1997). The dynamics of sarcoptic mange in the ibex population of Sierra Nevada in Spain - influence of climatic factors. J. Wildl. Res. 2, 86-89.

Pianka, E.R. \& Parker, W.S. (1975). Age specific reproductive tactics. Am. Nat. 109, 453-464.

Piersma, T. \& Drent, J. (2003). Phenotypic flexibility and the evolution of organismal design. Trends Ecol. Evol. 18, 228-233.

Piersma, T. \& Lindstrom, A. (1997). Rapid reversible changes in organ size as a component of adaptive behaviour. Trends Ecol. Evol. 12, 134-138.

Preston, B.T., Stevenson, I.R., Pemberton, J.M., Coltman, D.W. \& Wilson, K. (2003). Overt and covert competition in a promiscuous mammal: the importance of weaponry and testes size to male reproductive success. Proc. Roy. Soc. Lond. Ser. B. 270, 633-640.

Preston, B.T., Stevenson, I.R., Pemberton, J.M. \& Wilson, K. (2001). Dominant rams lose out by sperm depletion: a waning success in siring counters a ram's high score in competition for ewes. Nature 409, 681-682.

Reynolds, J. \& Harvey, P.H. (1994). Sexual selection and the evolution of sex differences. In The differences between the 
sexes: 53-70. Short, R.V. \& Balaban, E. (Eds). Cambridge: Cambridge University Press.

Schaller, G. (1977). Mountain monarchs. Wild sheep and goats of the Himalaya. Chicago: University of Chicago Press.

Scharer, L., Ladurner, P. \& Rieger, R.M. (2004). Bigger testes do work more: experimental evidence that testis size reflects testicular cell proliferation activity in the marine invertebrate, the free-living flatworm Macrostomum sp. Behav. Ecol. Sociobiol. 56, 420-425.

Scharer, L. \& Vizoso, D.B. (2007). Phenotypic plasticity in sperm production rate: there's more to it than testis size. Evol. Ecol. 21, 295-306.

Schulte-Hostedde, A.I. \& Millar, J.S. (2004). Intraspecific variation of testis size and sperm length in the yellow-pine chipmunk (Tamias amoenus): implications for sperm competition and reproductive success. Behav. Ecol. Sociobiol. 55, 272-277.

Schulte-Hostedde, A.I., Millar, J.S. \& Hickling, G.J. (2003). Intraspecific variation in testis size of small mammals: implications for muscle mass. Can. J. Zool. 81, 591-595.

Schulte-Hostedde, A.I., Millar, J.S. \& Hickling, G.J. (2005a). Condition dependence of testis size in small mammals. Evol. Ecol. Res. 7, 143-149.

Schulte-Hostedde, A.I., Zinner, B., Millar, J.S. \& Hickling, G.J. (2005b). Restitution of mass-size residuals: validating body condition indices. Ecology 86, 155-163.

Serrano, E., Gallego, L. \& Perez, J.M. (2004). Ossification of the appendicular skeleton in the Spanish ibex Capra pyrenaica Schinz 1838 (Artiodactyla: Bovidae), with regard to determination of age. Anat. Histol. Embryol. 33, 33-37.

Sinervo, B. \& Clobert, J. (2008). Life history strategies, multidimensional trade-offs and behavioural syndromes. In Behavioural ecology: an evolutionary perspective and behaviour: 135-183. Danchin, E., Giraldeau, L.A. \& Cezilly, F. (Eds). Oxford: Oxford University Press.

Tazzyman, S.J., Pizzari, T., Seymour, R.M. \& Pomiankowski, A. (2009). The evolution of continuous variation in ejaculate expenditure strategy. Am. Nat. 174, E71-E82.

Torgo, C., Gaillard, J.-M., Festa-Bianchet, M., Largo, E., Michallet, J. \& Maillard, D. (2007). Sex- and age-specific survival of the highly dimorphic alpine ibex: evidence for a conservative life-history tactic. J. Anim. Ecol. 76, 679-686.

Toledano-Diaz, A., Santiago-Moreno, J., Gomez-Brunet, A., Pulido-Pastor, A. \& Lopez-Sebastian, A. (2007). Horn growth related to testosterone secretion in two wild Mediterranean ruminants species: the Spanish ibex (Capra pyrenaica hispanica) and the European mouflon (Ovis orientalis musimon). Anim. Reprod. Sci. 102, 300-307.

Vanpe, C., Kjellander, P., Galan, M., Cosson, J.-F., Aulagnier, S., Liberg, O. \& Hewison, A.J.M. (2008). Mating system, sexual dimorphism, and the opportunity for sexual selection in a territorial ungulate. Behav. Ecol. 19, 309-316.

Williams, G.C. (1966). Natural selection, the costs of reproduction, and a refinement of lack's principle. Am. Nat. 100, 687-690.

Wood, S.N. (2006). Generalized additive models, an introduction with R. Boca Raton: Chapman and Hall/CRC.

Wroblewski, E., Murray, C.M., Keele, B.F., SchumacherStankey, J.C., Hahn, B.H. \& Pusey, A.E. (2009). Male dominance rank and reproductive success in chimpanzees, Pan troglodytes schweinfurthii. Anim. Behav. 77, 873-885.

Zuk, M. (1996). Disease, endocrine-immune interactions, and sexual selection. Ecology 77, 1037-1042.

Zuur, A.F., Ieno, E.N. \& Smith, G.M. (2007). Analysing ecological data. New York: Springer.

\section{Supporting information}

Additional Supporting Information may be found in the online version of this article:

Appendix S1. Data on testes and body mass in Iberian ibex (Sierra Nevada, Spain).

As a service to our authors and readers, this journal provides supporting information supplied by the authors. Such materials are peer-reviewed and may be re-organized for online delivery, but are not copy-edited or typeset. Technical support issues arising from supporting information (other than missing files) should be addressed to the authors. 